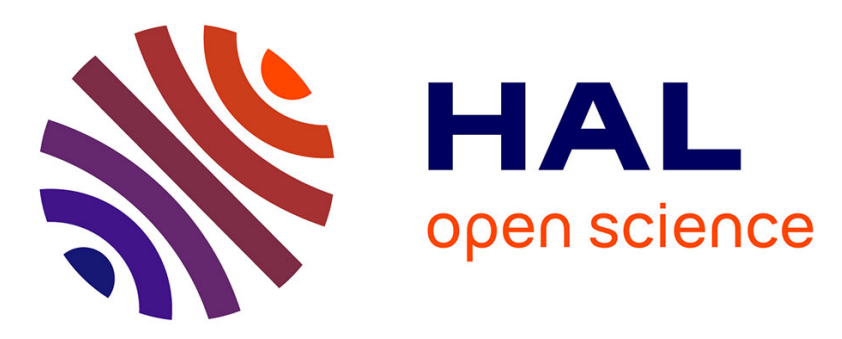

\title{
Study of drought impact on inland navigation systems based on a flow network model
}

\author{
Houda Nouasse, Lala Rajaoarisoa, Arnaud Doniec, Eric Duviella, Pascale \\ Chiron, Bernard Archimède, Karine Chuquet
}

\section{To cite this version:}

Houda Nouasse, Lala Rajaoarisoa, Arnaud Doniec, Eric Duviella, Pascale Chiron, et al.. Study of drought impact on inland navigation systems based on a flow network model. XXV International Conference on Information, Communication and Automation Technologies (ICAT), Oct 2015, Sarajevo, Bosnia and Herzegovina. pp. 150-155. hal-01308886

\section{HAL Id: hal-01308886 https://hal.science/hal-01308886}

Submitted on 28 Apr 2016

HAL is a multi-disciplinary open access archive for the deposit and dissemination of scientific research documents, whether they are published or not. The documents may come from teaching and research institutions in France or abroad, or from public or private research centers.
L'archive ouverte pluridisciplinaire HAL, est destinée au dépôt et à la diffusion de documents scientifiques de niveau recherche, publiés ou non, émanant des établissements d'enseignement et de recherche français ou étrangers, des laboratoires publics ou privés. 


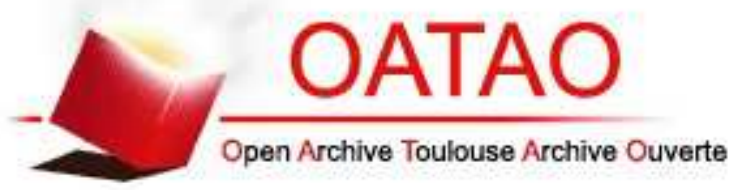

\section{Open Archive Toulouse Archive Ouverte (OATAO)}

OATAO is an open access repository that collects the work of Toulouse researchers and makes it freely available over the web where possible.

This is an author-deposited version published in: http://oatao.univ-toulouse.fr/ Eprints ID: 14715

\section{To cite this version:}

Nouasse, Houda and Rajaoarisoa, Lala and Doniec, Arnaud and Duviella, Eric and Chiron, Pascale and Archimède, Bernard and Chuquet, Karine Study of drought impact on inland navigation systems based on a flow network model. (2015) In: XXV International Conference on Information, Communication and Automation Technologies (ICAT), 29 October 2015 31 October 2015 (Sarajevo, Bosnia And Herzegovina). 


\section{Study of Drought Impact on Inland Navigation Systems based on a Flow Network Model}

\author{
Houda Nouasse, Lala Rajaoarisoa, Arnaud Doniec, Eric Duviella \\ Mines Douai, IA, Université de Lille, France \\ \{houda.nouasse,lala.rajaoarisoa,arnaud.doniec,eric.duviella\}@mines-douai.fr
}

\author{
Pascale Chiron, Bernard Archimède \\ ENIT-LGP, Tarbes, France \\ \{pascale.chiron,bernard.archimede\}@enit.fr
}

\author{
Karine Chuquet \\ Voies Navigables de France, Service de la navigation du nord, Lille, France \\ karine.chuquet@vnf.fr
}

\begin{abstract}
Inland navigation systems are large scale networks that are used for transport. The navigation can be accommodated if the navigation condition are gathered, i.e. if there is enough volume of water in each part of the network. Thus, it is necessary to supply the inland navigation networks with water and to well dispatch the available volume of water on the whole system. This aim is generally achieved without difficulty in normal condition. However, during drought periods, the available volume of water is decreasing and the navigation conditions would not be reached everytime. These situations are expected to be more current in the future specially in a global change context in which the frequency and the magnitude of drought events will increase. Hence, it is necessary to design some tools to study the resilience of inland navigation networks against drought events. For this purpose a flow network model, allowing to simulate the inland navigation systems, is proposed in this paper.
\end{abstract}

\section{INTRODUCTION}

Global change is studied since several years by national and intergovernmental panels as the IPCC (Intergovernmental Panel on Climate Change). The IPCC has defined the RCP scenarios (Representative Concentration Pathways) on which future forecasts on temperature and rain can be generated [12], [13]. Based on RCP scenarios, studies have been achieved and are available in the literature [3], [7]. A general agreement leads to the expectation of a global increase of the temperature with a modification of the rain distribution over seasons and areas by the end of the century. Thus, an increase of the frequency and intensity of flood and drought periods are expected [2]. By focalizing on drought events, the climate and Human impact on future hydrological drought across the world has been addressed in [21]. These drought events that can be characterized by multivariate drought indices [11], can be forecasted using RCP scenarios. Very recently, the RCP 8.5 scenario has been considered in [15] and [19] to quantify the frequency, duration and intensity of future drought events in several areas in China and Korea respectively.

Drought events will particularly impact inland navigation networks as it is shown in [9], [14]. Indeed, the available volume of water that are necessary to supply the inland navigation networks will decrease during drought periods. The study of inland navigation networks in UK [1] and in China [22] leads to the same conclusion. The constraints on water for navigation will be bigger in the future. Hence, it is necessary to anticipate this impact, to determine the resilience of the inland navigation networks against the drought periods and to propose adaptive management strategies that allow to reduce their vulnerability. In [8], a multi-scale modeling approach is designed to reproduce the dynamics of inland navigation networks considering flood and drought events. The main idea is to consider the inland navigation network dynamics with different time and spatial scales. Indeed, drought events should impact larger areas on larger periods than flood events. To consider these larger scales, the drought model is designed with a sample time of one day by considering a large part of the inland navigation networks. It consists in considering volumes as dynamical variables. Based on the knowledge on the dynamics of inland navigation networks, it is possible to determine their resilience against drought period. Drought scenarios have to be determined and simulated to highlight the parts of the network that are the most vulnerables. In this way, it is possible to know if the navigation conditions could be gathered. A flow network model is used to simulate the determined drought scenarios. Network flow problems since the 60's, have been widely used for the computation of maximum flow or minimum cost flow in several areas such as transportation [20], telecommunication [10] and job scheduling. Network flow theory have been evolved during these last decades, as new problems have been discussed and studied. Most of these problems concern: the flow over time, the multicommodity flow, the network flow design and its impact on complexity and constraints and/or demands uncertainties. We can find in literature examples of the use of network flow models in water resources management in particular for flood attenuation [5], [18].

In this paper, the problem formulation of the inland navigation network management during drought periods is presented in Section II. An integrated model is proposed in Section III. It is used to represent the configuration of the inland navigation systems and to identify all the flow inputs and outputs. Section IV is dedicated to the description of the flow network model. Finally, an academical case study that is built by considering realistic data is proposed to show the effectiveness of the proposed method.

\section{Problem Statement}

Inland navigation networks are large scale systems principally used for navigation task. In Europe, they cover large territories and are integrated in the Trans-European network 
$\left(\mathrm{TEN}-\mathrm{T}^{1}\right)$ (see Figure 1). They provide economic and environmental benefits [17], [16], by offering an efficient, quieter, and safer transport of goods [4].

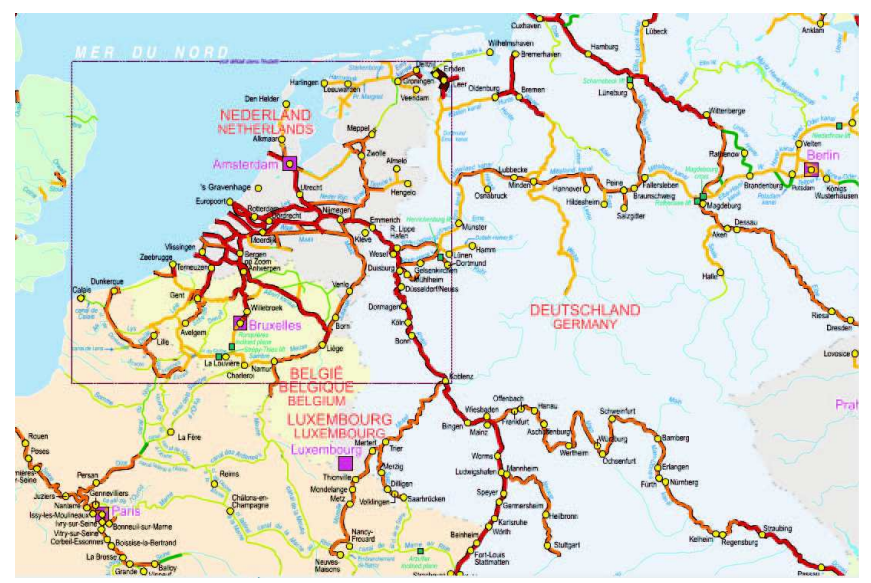

Fig. 1. European waterways ${ }^{2}$

In the north of France, the inland navigation network allows navigation from north of Paris to north of Europe, i.e. Belgium, the Netherlands. Most parts of this waterway are composed of canalized rivers and artificial channels. It covers three watersheds and it is equipped with more than fifty locks. A part of an inland navigation network between two locks is defined as a Navigation Reach (NR).

The artificial channels have to be supplied with natural rivers. Indeed, the navigation can be accommodated only if the water level in each NR is inside the navigation rectangle (see Figure 2) and close to the Normal Navigation Level (NNL). The main management objective consists in maintaining the level of each NR close to the NNL. The boundaries of the navigation rectangle are the High Navigation Level (HNL) and the Low Navigation Level (LNL).

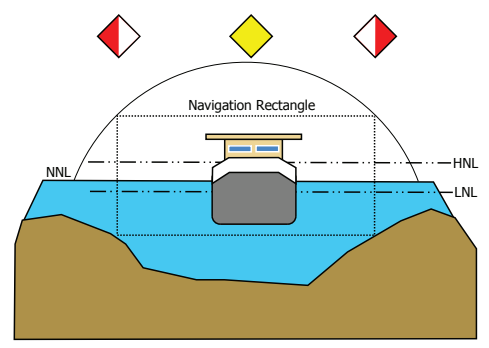

Fig. 2. Navigation rectangle with high and low limits.

The water level of a NR is principally disturbed by the lock operations. When a ship is crossing a lock, a water volume empties the upstream NR and supplies downstream NR in few minutes. This water volume depends directly from the size of the lock. Moreover, some of these NR are supplied by exchanges with groundwater and by natural rivers. To maintain the NNL, it is thus necessary to control the water flow of

\footnotetext{
${ }^{1}$ http://ec.europa.eu/transport/themes/infrastructure/ten-t-guidelines/index_ en.htm

${ }^{2}$ http://www.vnf.fr/vnf/img/cms/Tourisme_et_domainehidden/carte_france_ europe_transport_deux_mille_onze_201101041503.pdf
}

the gates that are usually located beside the locks. When the discharges from these gates are not sufficient, water intakes from natural rivers can supply the NR. On the contrary, if the water supply from a lock operation is too high, gates can be controlled to empty the NR by rejecting the water in natural rivers. These management rules are dependent from the available equipment and the configuration of the inland navigation networks.

The navigation schedules correspond to 12 hours each day, they are limited on sunday, and they are closed a couple of days each year. Due to the water consumption of the locks, and the available water resource, the inland navigation networks have a finite navigation capacity (NC). The NC corresponds to the maximum number of ships that can cross each navigation path. In normal situation, these $\mathrm{NC}$ can be determined and the average number of ships that cross each lock daily can be determined according to real data. In drought period, the available water resource will decrease and the NC should also decrease. Thus, the main objective is to determine if the NC will be impacted during drought events and to determine these new NC values. Hence, an integrated model of inland navigation networks is proposed to represent their configuration, to identify the water intakes and all the NR equipment, i.e. gates, locks. It is then necessary to determine the minimal and maximal daily volumes of the water intakes and all the NR equipment. Finally, a flow network model is designed to simulate the daily dynamics of the inland navigation networks.

\section{INTEGRATED MODEL}

The integrated model is proposed to model several configurations of inland navigation networks by considering two elementary configurations: a confluence and a diffluence (see Figure 3.a). The networks are composed with a finite number $\eta$ of interconnected NR. NR are numbered and denoted $N R_{i}$, with $i \in 1$ to $\eta$. The $N R_{i}$ is modeled as a tank that contains a volume of water, denoted $V_{i}(t)$. According to the boundaries of the navigation rectangle, to the NNL and to the geometrical characteristics of each $N R_{i}$, it is possible to determine the volumes that corresponds to the NNL, the HNL and the LNL such as $V_{i}^{L N L} \leq V_{i}^{N N L} \leq V_{i}^{H N L}$. The management objective is $V_{i}(t)=V_{i}^{N N L}$ and at least $V_{i}^{L N L} \leq V_{i}(t) \leq V_{i}^{H N L}$. If this condition is broken, the navigation has to stop.

A $N R_{i}$ is supplied and is emptied by controlled and uncontrolled water volumes (see Figure 3.b). Controlled water volumes gather the water that is coming from controlled gates and from the lock operations. Uncontrolled water volumes are all the withdrawals and supplies from water intakes located along the $N R_{i}$. It is also possible to consider the water exchanges with groundwater.

Thus, the set of controlled water volumes is composed of:

- $\quad$ controlled volumes from the upstream NR that supply the $N R_{i}$, denoted $V_{i}^{s, c}$ ( $s$ : supply, $c$ : controlled),

- controlled volumes from the $N R_{i}$ that empty the $N R_{i}$, denoted $V_{i}^{e, c}$ (e: empty),

- controlled volumes from water intakes that can supply or empty the $N R_{i}$, denoted $V_{i}^{c}$. These volumes are 

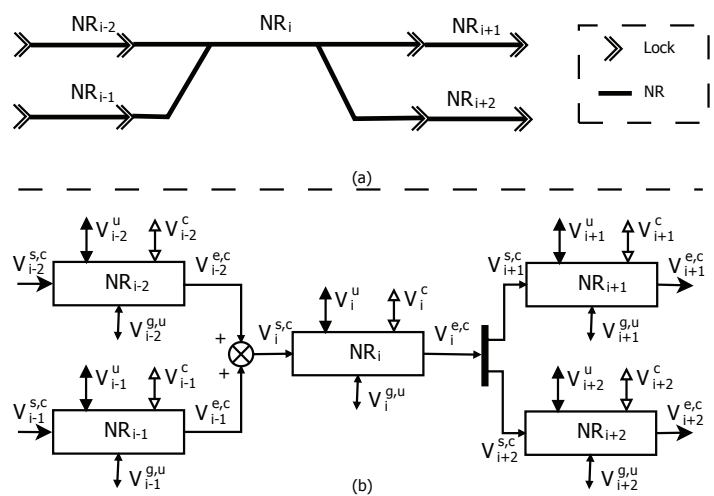

Fig. 3. (a) Inland navigation network, (b) its integrated model.

signed; positive if the $N R_{i}$ is supplied, negative otherwize.

The set of uncontrolled water volumes is composed of:

- uncontrolled volumes from natural rivers, rainfallrunoff, Human uses, denoted $V_{i}^{u}$ ( $u$ : uncontrolled). These volumes are signed depending of their contribution to the volume $V_{i}(t)$ in the $N R_{i}$.

- uncontrolled volumes from exchanges with groundwater, denoted $V_{i}^{g, u}$ ( $g$ : groundwater). These volumes are also signed.

Based on the definition of the water volumes that contribute to the volume contained in the $N R_{i}$, it is possible to model its dynamics by:

$$
\begin{aligned}
V_{i}(t)=V_{i}(t-1) & +V_{i}^{s, c}(t)-V_{i}^{e, c}(t)+V_{i}^{c}(t) \\
& +V_{i}^{u}(t)+V_{i}^{g, u}(t)
\end{aligned}
$$

The dynamics of the $N R_{i}$ have to take into account the configuration of the network. For a confluence, the controlled volumes coming from all the NR that are located upstream the $N R_{i}$ are added. For a diffluence, the controlled volumes that empty the $N R_{i}$ correspond to the sum of the controlled volumes that supply the downstream NR (see relation (2)).

$$
\left\{\begin{array}{l}
V_{i}^{s, c}(t)=\sum_{j \in \Omega_{i}} V_{j}^{e, c}(t), \\
V_{i}^{e, c}(t)=\sum_{j \in \Theta_{i}} V_{j}^{s, c}(t),
\end{array}\right.
$$

where $\Omega_{i}$ gathers all the index of the NR that supply the $N R_{i}$, and $\Theta_{i}$ all the index of the NR that are supplied by the $N R_{i}$.

The proposed integrated model requires the knowledge of all the possible water volume contributions. It is necessary to identify all the controlled volumes and to estimate all the uncontrolled volumes. This knowledge comes from the expert knowledge of the inland navigation network managers, and can be issued from the available measured data.

In this paper, we propose to set some assumptions for the study of the impact of drought on inland navigation networks. Water exchanges with groundwater are nonexistent. The uncontrolled water volumes $V_{i}^{u}$ are not considered. The controlled water volumes $V_{i}^{c}$ from water intakes are bounded with the known minimal and maximal daily volumes of water. The water volume that corresponds to each lock operation is known. Finally, the daily average number of ships that cross the inland navigation network is known.

A flow network model is introduced to implement the proposed integrated model and to study the impact of drought. This model is described in the next section.

\section{Flow NeTWORK MODEL}

Let consider a network, $\mathcal{G}=\left(\mathcal{G}_{x} ; \mathcal{G}_{a}\right)$, defined as a connected Directed Acyclic Graph (DAG), where $\mathcal{G}_{x}$ is the set of nodes and $\mathcal{G}_{a}$ is the set of arcs. The set of nodes $\mathcal{G}_{x}$ contains the nodes representing each reach in the navigation network $N R_{i}$ and two additional nodes, $O$ and $N$, called respectively source and sink. A directed arc is defined between two nodes as a couple $a=(i, j)$, with $i$ the node that is leaving and $j$ the node that is entering. For the sake of clarity, the name of the node corresponds to the index of the $N R$, i.e. $a=\left(N R_{i}, N R_{j}\right)=(i, j)$ or $a=\left(O, N R_{j}\right)=(O, j)$. On every arc in $\mathcal{G}_{a}$, it is defined a flow variable $\phi_{a}, a \in \mathcal{G}_{a}$ that can be expressed by $\phi_{i j}$. This flow varies with respect to capacities constraints and demands relation on each node. Figure 4 shows an exemple of a flow network model by considering the navigation network proposed in Figure 3. The arcs are directed according to the configuration of the navigation network. According to the proposed assumptions, the node $O$ gathers all the volumes of water that supply the navigation network from natural rivers. The node $N$ retrieves all the volumes of water from the navigation network.

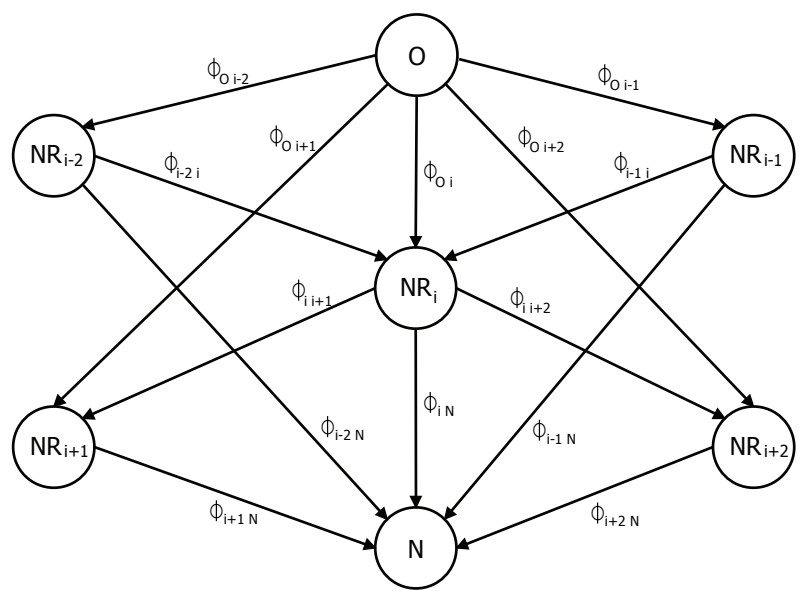

Fig. 4. Flow Network Model.

A flow $\phi_{a} \in \mathbb{R}$ is feasible if and only if it satisfies the capacity constraint on each arc of $\mathcal{G}_{a}$. This flow is optimal if and only if its residual graph contains no augmenting path. An augmenting path is a source to sink path in the residual graph.

The formulation we propose in this work consists in finding the flow in the network $\mathcal{G}$ that guaranties different navigation scenarios for one day period time ( 24 hours):

Maximize $\Phi$

subject to

$$
\left\{\begin{array}{c}
l_{a} \leq \phi_{a} \leq u_{a} \text { for } a \in \mathcal{G}_{a} \\
\Phi \geq 0
\end{array}\right.
$$


by considering these additional contraints

$$
\phi_{a^{+}}-\phi_{a^{-}}=d(i) \text { for } i \in \mathcal{G}_{x}-\{O, N\}
$$

where $\Phi$ is a vector that contains all the flow $\phi_{a}, l_{a}$ and $u_{a}$ the lower and upper bound capacities of the arc $a, a^{+}$the arcs leaving the node $i$ and $a^{-}$, the arcs entering the node $i$, and $d(i)$ the demand of the node $i$. We also assume that $\phi_{a^{+}}(O)=d(O)$ and $\phi_{a^{-}}(N)=-d(O)$ as $d(O)$ is the known supply on the source node.

In order to respect the navigation conditions on each reach $N R_{i}$, the demand of water volumes on each node representing a $N R$ is defined as:

$$
d(i)=V_{i}^{N N L}-V_{i}(t), \quad i \in \mathcal{G}_{x}-\{O, N\}
$$

that must verify the following relation:

$V_{i}^{N N L}-V_{i}^{H N L} \leq d(i) \leq V_{i}^{N N L}-V_{i}^{L N L} i \in \mathcal{G}_{x}-\{O, N\}$

The design of the integrated model (see Figure 3.b) helps to build the flow network and to determine the capacities that are expressed in volume. The lower and upper bound capacities of the arc a, i.e. $l_{a}$ and $u_{a}$, depend on the configuration and equipment of the inland navigation networks. Hence, we define $\Psi$ the set of the index of the upstream $N R$ that are not supplied by another $N R$, and $\Xi$ the set of the index of the downstream $N R$ that not supply another $N R$. By considering example in Figures 3 and 4 , these sets are $\Psi=\{i-2, i-1\}$, and $\Xi=$ $\{i+1, i+2\}$. Thus:

- upper bound capacities for arcs between two $N R$, i.e. $\{(i-2, i),(i-1, i),(i, i+1),(i, i+2)\}$ in Figure 4 , between $O$ and $N R_{j}, j \in \Psi$, i.e. $\{(O, i-2),(O, i-1)\}$, and between $N$ and $N R_{l}$, $l \in \Xi$, i.e. $\{(i+1, N),(i+2, N)\}$, are computed as the sum of the maximum available water volumes from water intakes (maximum positive $V_{i}^{c}$ ) and the required water volumes for the navigation, i.e. $b \in \mathbb{N}$ the number of ships that cross each $N R\left(V_{i}^{s, c}\right)$,

- $\quad$ upper bound capacities for arcs between $O$ and $N R_{j}$, $j \notin \Psi$, i.e. $\{(O, i),(O, i+1),(O, i+2)\}$, correspond to the sum of the maximum available water volumes from water intakes (maximum positive $V_{i}^{c}$ ),

- $\quad$ upper bound capacities for arcs between $N$ and $N R_{j}$, $j \notin \Xi$, i.e. $\{(i-2, N),(i-1, N),(i, N)\}$, correspond to the sum of the maximum water volumes that can empty the $N R$ (minimum negative $V_{i}^{c}$ ),

- lower bound capacities for arcs between two $N R$, between $O$ and $N R_{j}, j \in \Psi$, and between $N$ and $N R_{l}, l \in \Xi$, are only the required water volumes for the $b \in \mathbb{N}$ ships that cross the $N R\left(V_{i}^{s, c}\right)$,

- lower bound capacities for arcs between $O$ and the $N R_{j}, j \notin \Psi$, and between $N$ and the $N R_{l}, l \in \Xi$ are equal to 0 .

In the following, we propose a constraint programming (CP) approach to determine the resilience of our system in the flow network $\mathcal{G}$ under the previous formulation. Constraint programming is a powerful tool to deal with difficult problems especially in areas of planning and scheduling. It combines the use of a natural and elegant declarative formulation of problem with effective solving algorithm [6]. The formulation in CP consist in constraint satisfaction problems (CSP), i.e a set of variables taking their value in a finite domain and subject to a finite set of constraints. Solving a CSP requires to find for each variable a value in its domain which is consistent with all constraints (i.e. which does not violate any constraint of the problem).

For each period, we formulate and solve a constraint satisfaction problem:

- variables are the $\phi_{a}, a \in \mathcal{G}_{a}$,

- $\quad$ each $\phi_{a}$ has a finite domain expressed as a discrete interval whose bound are calculated according to the number of ships $b$,

- these values are constrained by relations between entering and leaving flow on each node of $\mathcal{G}_{x}$.

The following algorithm show how constraint programming is integrated to calculate the maximum flow.

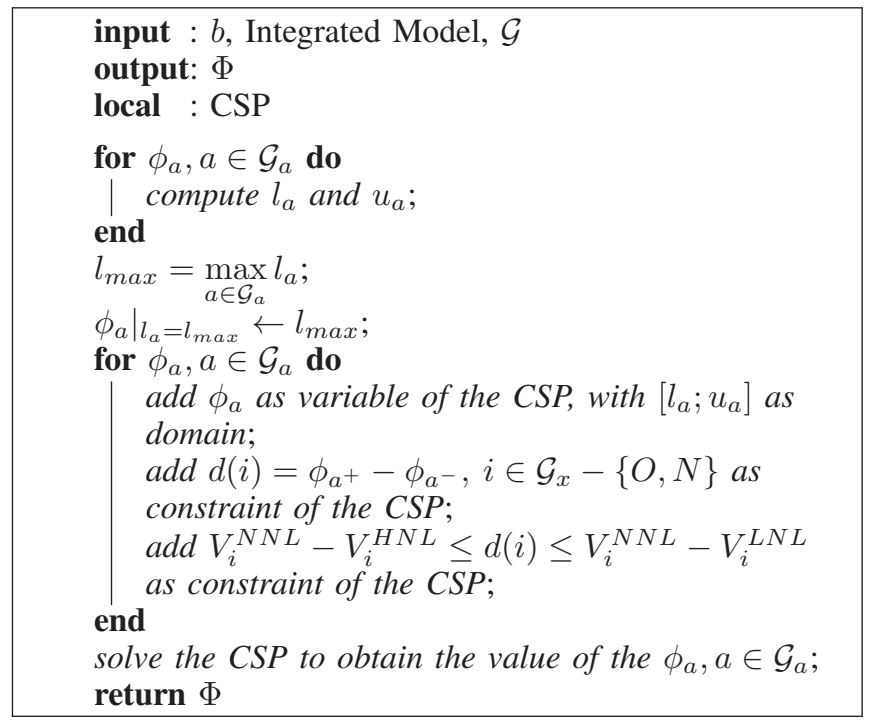

\section{ACADEMICAL CASE STUDY}

The proposed case study is an inland navigation network composed of $2 \mathrm{NR} ; N R_{1}$ between the locks $L_{1}$ and $L_{2}$ and $N R_{2}$ between the locks $L_{2}$ and $L_{3}$ (see Figure 5.a). The gate $G_{12}$ is used to supply the $N R_{2}$ with water from $N R_{1}$. The proposed integrated model is depicted in Figure 5.b, with the volumes of water that suply and empty each NR.

$N R_{1}$ is supplied by operations of the lock $L_{1}$ with a daily volume $V_{1}^{s, c}\left(=V_{1}^{s, c, L}\right)$. $N R_{2}$ is supplied by operations of the lock $L_{2}$ with a daily volume $V_{2}^{s, c, L}$, and by the gate $G_{12}$ with a daily volume $V_{2}^{s, c, G}$. Due to the configuration of the network, note that the volume from $N R_{1}$ that supplied $N R_{2}$, i.e. $V_{2}^{s, c}$, is equal to the volume that empties $N R_{1}$, i.e. $V_{1}^{e, c}$. The volume from $N R_{1}$ that supplied $N R_{2}$, i.e. $V_{2}^{s, c}$, is also equal to the sum of $V_{2}^{s, c, L}$ and $V_{2}^{s, c, G}$. This differentiation is made to simplify the identification of the volume from the lock $L_{2}$ operation to the volume from the gate $G_{12}$ operation. 
$N R_{2}$ is emptied by the operation of the lock $L_{3}$ with a daily water of volume $V_{2}^{e, c}$.

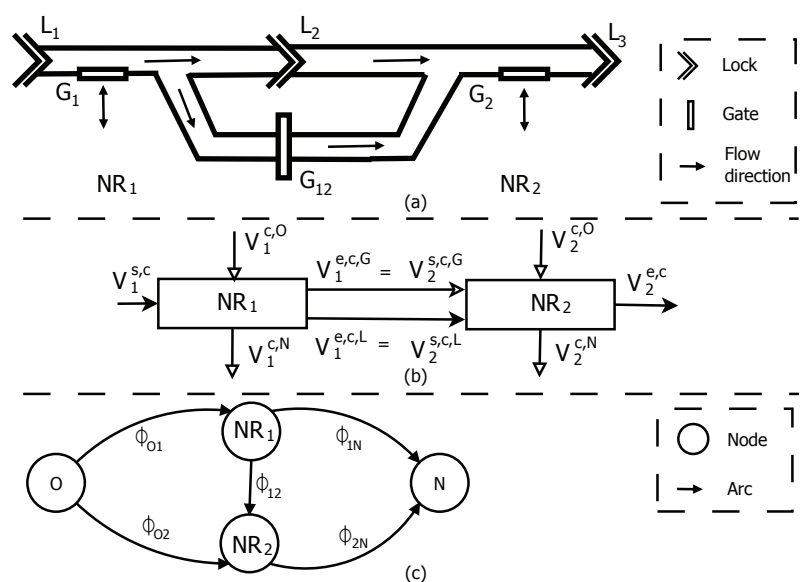

Fig. 5. (a) Inland navigation network composed of $2 \mathrm{NR},(b)$ the corresponding integrated model, $(c)$ the corresponding flow network.

The $N R_{1}$ (resp. $N R_{2}$ ) is equipped with a controlled gate $G_{1}$ (resp. $G_{2}$ ). The gate $G_{1}$ (resp. $G_{2}$ ) allows supplying and emptying the $N R_{1}$ (resp. $N R_{2}$ ) with the signed volume $V_{1}^{c}$ (resp. $V_{2}^{c}$ ). To distinct if the volume is supplying or is emptying the $N R$, we introduce $V_{1}^{c, O}$ (resp. $V_{2}^{c, O}$ ) defined as the volume that supplies the $N R_{1}$ (resp. $N R_{2}$ ), and $V_{1}^{c, N}$ (resp. $V_{2}^{c, N}$ ) defined as the volume that empties the $N R_{1}$ (resp. $N R_{2}$ ). These volumes are distinguished to simplify the design of the flow network model (see Figure 5.c), and to identify the flow conditions of each arc $\phi_{i j}$.

\section{A. Study in a normal situation}

Let's define the physical characteristics of the inland navigation network. $N R_{1}$ is $50 \mathrm{~km}$ long with a width of $50 \mathrm{~m}$. $\mathrm{NR}_{2}$ is $42 \mathrm{~km}$ long with a width of $50 \mathrm{~m}$. The water depth is $4.5 \mathrm{~m}$ for $N R_{1}$ and $4.26 \mathrm{~m}$ for $N R_{2}$. The volumes of water that are contained in the two NR for the $N N L$ are expressed in thousand of $m^{3}$ by:

- $V_{1}^{N N L}=11,250$,

- $V_{2}^{N N L}=8,946$.

The navigation rectangle is defined by $H N L=N N L+$ $30 \mathrm{~cm}$ and $L N L=N N L-20 \mathrm{~cm}$. Thus, the navigation conditions are (thousand of $\mathrm{m}^{3}$ ):

- $10,750 \leq V_{1}^{N N L} \leq 12,000$,

- $8,526 \leq V_{2}^{N N L} \leq 9,576$.

The demand of each $N R$ is defined by $d(1)=V_{1}^{N N L}$ $V_{1}(t)$, and $d(2)=V_{2}^{N N L}-V_{2}(t)$, leading to: $-750 \leq d(1) \leq$ 500 and $-630 \leq d(2) \leq 420$. Thus, if the navigation objective is achieved, these demands are equal to 0 .

The volume of water due to lock operations depends on the number of ship, denoted $b$, that cross the lock each day, and on the dimension of the locks. Volumes for each lock is given in thousand of $m^{3}$ by:

- $V_{1}^{s, c}=5 \times b \mathrm{~m}^{3}$,
- $\quad V_{1}^{e, c, L}=V_{2}^{s, c, L}=3.7 \times b m^{3}$,

- $V_{2}^{e, c}=25 \times b \mathrm{~m}^{3}$.

The water volumes from the gates are computed according to the knowledge of their operating modes given by the available discharges in a normal situation:

- $G_{1}:[-2 ; 2] \mathrm{m}^{3} / \mathrm{s}$, leading to $V_{1}^{c, O} \in[0 ; 172.8]$ and $V_{1}^{c, N} \in[-172.8 ; 0]$ (thousand of $m^{3}$ ),

- $G_{12}:[0 ; 2] \mathrm{m}^{3} / \mathrm{s}$, leading to $V_{1}^{e, c, G}=V_{2}^{s, c, G} \in$ $[0 ; 172.8]$,

- $G_{2}:[-7 ; 7] \mathrm{m}^{3} / \mathrm{s}$, leading to $V_{2}^{c, O} \in[0 ; 604.8]$ and $V_{2}^{c, N} \in[-604.8 ; 0]$.

According to the data from the daily available volumes of water, it is possible to determine the flow conditions of each arc of $\mathcal{G}$, that are expressed in thousand of $m^{3}$ (see Figure 5.c):

- $\phi_{O 1} \in[5 \times b ; 5 \times b+172.8]$,

- $\phi_{O 2} \in[0 ; 604.8]$,

- $\phi_{12} \in[3.7 \times b ; 3.7 \times b+172.8]$,

- $\phi_{1 N} \in[0 ; 172.8]$,

- $\phi_{2 N} \in[25 \times b ; 25 \times b+604.8]$.

The first simulated scenario consists in $b=5$ ships crossing the considered navigation system. Considering the daily available volumes of water and this number of ships, lower and upper bound capacities are determined and shown in Figure 6.a. The flow between nodes $N R_{2}$ and $N$ is fixed to the maximum of the lower bound capacities, i.e. $\phi_{2 N}=125$, because the most constrained part of the system is the lock $L_{3}$. Then, the proposed algorithm is used to determine the flows. For this scenario, only one path is used. It is highlighted in red line with the computed value of the flow crossing each arc on his path. The volume that goes from $O$ to $N$ is 125 .

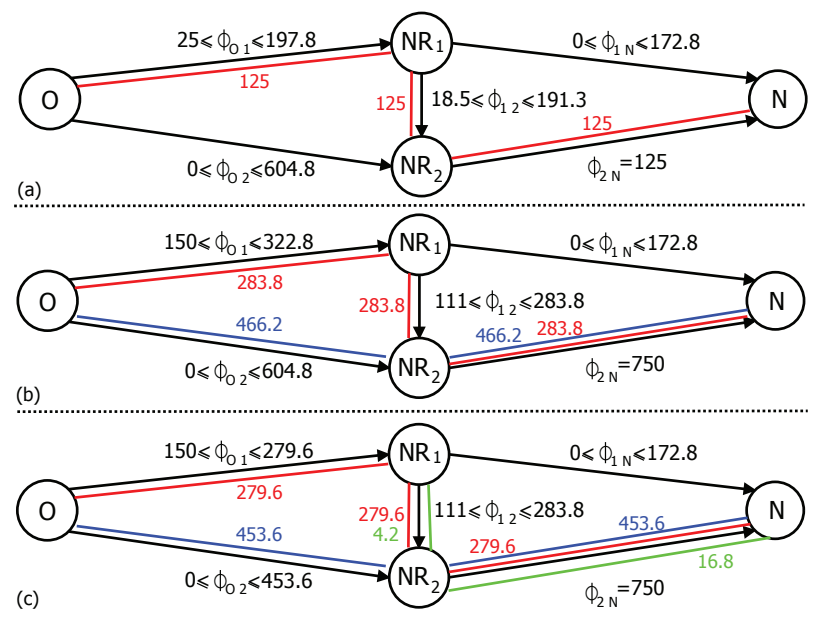

Fig. 6. (a) Scenario with $b=5$ in a normal situation, (b) scenario with $b=30$ in a normal situation, (c) scenario with $b=30$ in a drought situation.

The second simulated scenario consists in $b=30$ ships. Lower and upper bound capacities are determined and shown 
in Figure 6.b. For this scenario, the flow between nodes $N R_{2}$ and $N$ is $\phi_{2 N}=750$. In this case, two paths are used. The first one is highlighted in red line. The flow that is transfered through this path is constrained by the upper bound capacity of $\phi_{12}=283.8$. The second path is highlighted in blue line and correspond to a flow of $\phi_{02}=466.2$, i.e. a discharge of 6.82 $\mathrm{m}^{3} / \mathrm{s}$ during all the day. Thus, the constraint of $\phi_{2 N}=750$ is respected.

\section{B. Study in a drought situation}

In drought situation, it is considered that the available resource from natural rivers is decreasing. That means that the water volumes from the gates are decreasing too. By expected a fall in available water of $25 \%$, the impacted flow conditions are:

$$
\begin{array}{ll}
\text { - } & \phi_{O 1} \in[5 \times b ; 5 \times b+129.6], \\
\text { - } & \phi_{O 2} \in[0 ; 453.6] .
\end{array}
$$

The third simulated scenario consists in $b=30$ ships in a drought situation. Lower and upper bound capacities are determined and shown in Figure 6.c. For this scenario, two paths are also used. The first one is highlighted in red line. In this case, the flow that is transfered through this path is constrained by the upper bound capacity of $\phi_{O 1}=279.6$. The second path is highlighted in blue line and correspond to a maximum flow of $\phi_{02}=453.6$, i.e. a maximum discharge of $5.25 \mathrm{~m}^{3} / \mathrm{s}$ during all the day. Nevertheless, the constraint of $\phi_{2 N}=750$ is not respected. To accommodate the navigation, it is necessary to use a part of the volume contained into $N R_{1}$ and $N R_{2}$. The volume from $N R_{1}$ is equal to 4.2 , this from $N R_{2}$ is equal to 12.6. It is represented in green line in Figure 6.c. The consequence is that the volumes $V_{1}(t)$ and $V_{2}(t)$ are not equal to $V_{1}^{N N L}$ and $V_{2}^{N N L}$. The day after, in addition to accommodate the navigation of the ships with the water volume transfers, it is necessary to supply the $N R_{1}$ and $N R_{2}$ in order to retrieve the setpoints $V_{1}^{N N L}$ and $V_{2}^{N N L}$.

\section{CONCLUSION}

In this paper, a study of the drought impact on inland navigation systems is presented. It is based on the proposal of an integrated model and on the design of a flow network. The flow network is used to determine the resilience of the inland navigation systems. In future works, the uncontrolled water volumes will be taken into account by considering a real inland navigation systems.

\section{ACKNOWLEDGMENT}

This work is a contribution to the GEPET-Eau project (http://gepeteau.wordpress.com/enversion/) which is granted by the French ministry MEDDE - GICC, the French institution ORNERC and the DGITM.

\section{REFERENCES}

[1] B.P. Arkell and G.J.C. Darch, Impact of climate change on London's transport network. Proceedings of the ICE - Municipal Engineer, Volume 159, Issue 4, Pages 231-237, 2006.

[2] B. Bates, Z. Kundzewicz, S. Wu and J. Palutikof, Climate change and water, Technical repport, Intergovernmental Panel on Climate Change, Geneva, 2008.
[3] J. Boé, L. Terray, E. Martin and F. Habetsi, Projected changes in components of the hydrological cycle in French river basins during the 21st century. Water Resources Research, Volume 45, 2009.

[4] C. Brand, M. Tran and J. Anable, The UK transport carbon model: An integrated life cycle approach to explore low carbon futures, Energy Policy, Volume 41, Pages 107-124, February 2012.

[5] B. Cui, C. Wang, W. Tao and Z. You, River channel network design for drought and flood control: A case study of Xiaoqinghe River basin, Jinan City, China, Journal of Environmental Management, Volume 90, Issue 11, Pages 3675-3686, 2009.

[6] R. Dechter, Constraint processing, Morgan Kaufmann, 2003.

[7] A. Ducharne, F. Habets, C. Pagé, E. Sauquet, P. Viennot, M. Déqué, S. Gascoin, A. Hachour, E. Martin, L. Oudin, L. Terray and D. Thiéry, Climate change impacts on Water Resources and Hydrological Extremes in Northern France. XVIII Conference on Computational Methods in Water Resources, June, Barcelona, Spain, 2010.

[8] E. Duviella, K. Horvàth, L. Rajaoarisoa and K. Chuquet, Multi-scale modeling approaches of inland navigation networks for their management in a global change context, Transport Research Arena, Paris La Défense, France, 2014.

[9] EnviCom - Task Group 3, Climate Change and Navigation - Waterborne transport, ports and waterways: A review of climate change drivers, impacts, responses and mitigation, EnviCom TG 3 - Issue 2008.

[10] S. Fekete, A. Hall, E. Köhler and A. Kröller, The maximum energyconstrained dynamic flow problem, in Gudmundsson, J., editor, Algorithm Theory-SWAT 2008, Volume 5124 of Lecture Notes in Computer Science, Pages 114-126. Springer Berlin Heidelberg, 2008.

[11] Z. Hao and V. P. Singh, Drought characterization from a multivariate perspective: A review, Journal of Hydrology, Volume 527, Pages 668678, 2015.

[12] IPCC, Summary for policymakers. In: Stocker, T.F., Qin, D., Plattner, G.-K., Tignor, M., Allen, S.K., Boschung, J., Nauels, A., Xia, Y., Bex, V., Midgley, P.M. (Eds.), Climate Change 2013: The Physical Science Basis. Contribution of Working Group I to the Fifth Assessment Report of the Intergovernmental Panel on Climate Change. Cambridge University Press, Cambridge, UK and NY, 2013.

[13] IPCC, Climate Change 2014. The Core Writing Team, R. K. Pachauri and L. Meyer, Synthesis Report, https://www.ipcc.ch/pdf/ assessment-report/ar5/syr/SYR_AR5_FINAL_full.pdf, 2014.

[14] IWAC Inland Waterways Advisory Council,Climate change mitigation and adaptation. Implications for inland waterways in England and Wales, 2009.

[15] Y. Li, H. Huang, H. Ju, E. Lin, W. Xiong, X. Han, H. Wang, Z. Peng, Y. Wang, J. Xu, Y. Cao and W. Hu, Assessing vulnerability and adaptive capacity to potential drought for winter-wheat under the RCP 8.5 scenario in the Huang-Huai-Hai Plain, Agriculture, Ecosystems \& Environment, 2015.

[16] I. Mallidis, R. Dekker and D. Vlachos, The impact of greening on supply chain design and cost: a case for a developing region, Journal of Transport Geography, Volume 22, Pages 118-128, May 2012.

[17] S. Mihic, M. Golusin and M. Mihajlovic, Policy and promotion of sustainable inland waterway transport in Europe - Danube River, Renewable and Sustainable Energy Reviews, Volume 15, Issue 4, Pages 1801-1809, May 2011.

[18] H. Nouasse, P. Chiron, and B. Archimède, A flood lamination strategy based on transportation network with time delay, Water Science Technology Water Supply, Volume 68, Issue 8, Pages 1668-1696, 2013.

[19] C.-K. Park, H.-R. Byun, R. Deo and B.-R. Lee, Drought prediction till 2100 under $\{R C P\} 8.5$ climate change scenarios for Korea, Journal of Hydrology, Volume 526, Pages 221-230, 2015.

[20] M. Silver and O. de Weck, Time-expanded decision networks: A framework for designing evolvable complex systems, Systems Engineering, Volume 10, Issue 2, Pages 167-188, 2007.

[21] N. Wanders and Y. Wada, Human and climate impacts on the $21^{\text {st }}$ century hydrological drought, Journal of Hydrology, Volume 526, Pages 208-220, 2015.

[22] S. Wang, S. Kang, L. Zhang and F. Li, Modelling hydrological response to different land-use and climate change scenarios in the Zamu River basin of northwest China. Hydrological Processes, Volume 22, Issue 14, Pages 2502-2510, 2007. 